\title{
As marcas das metamorfoses do capitalismo contemporâneo e suas implicações no espaço geográfico: o caso do Wal-Mart
}

Metamorphosis in the contemporary capitalism and their implications in the geographical space : the Wal-Mart's case

Les métamorphoses du capitalisme contemporain et leurs impacts sur l'espace géographique : le cas de Wal-Mart

Pedro Henrique Ferreira Costa e Paulo Roberto Teixeira Godoy

\section{(2) OpenEdition}

\section{Journals}

\section{Edição electrónica}

URL: http://journals.openedition.org/espacoeconomia/114

DOI: 10.4000/espacoeconomia.114

ISSN: 2317-7837

Editora

Núcleo de Pesquisa Espaço \& Economia

Refêrencia eletrónica

Pedro Henrique Ferreira Costa e Paulo Roberto Teixeira Godoy, « As marcas das metamorfoses do capitalismo contemporâneo e suas implicações no espaço geográfico: o caso do Wal-Mart », Espaço e Economia [Online], 1 | 2012, posto online no dia 09 março 2013, consultado o 30 abril 2019. URL : http://journals.openedition.org/espacoeconomia/114; DOI : 10.4000/espacoeconomia.114

Este documento foi criado de forma automática no dia 30 Abril 2019. 


\title{
As marcas das metamorfoses do capitalismo contemporâneo e suas implicações no espaço geográfico: o caso do Wal-Mart
}

\author{
Metamorphosis in the contemporary capitalism and their implications in the \\ geographical space : the Wal-Mart's case \\ Les métamorphoses du capitalisme contemporain et leurs impacts sur l'espace \\ géographique : le cas de Wal-Mart
}

Pedro Henrique Ferreira Costa e Paulo Roberto Teixeira Godoy

\section{Introdução}

1 A pesquisa em pauta teve como intenção central a investigação acerca das transformações do capitalismo contemporâneo, sob uma concepção histórica e geográfica. Para tanto, delinearam-se algumas considerações gerais a respeito da rede varejista norte-americana Wal-Mart, como ferramenta para a análise do tema em curso.

2 A expressão "contemporâneo", aplicar-se-á em relação a toda uma época, a qual acusa mudanças socioculturais, econômica e política. $\mathrm{E}$, no entanto, deram forma às maneiras com as quais a sociedade convive no espaço de uma geração. (NUNES, 1991). Desta forma, o capitalismo contemporâneo, para os fins deste estudo remete-nos à segunda metade do século XX, no qual transformou tanto os processos produtivos quanto as relações sociais e de governo.

3 A formação e a expansão do modo de produção capitalista no mundo, no decorrer dos séculos, implicaram em um aumento dos meios de acumulação primitiva, de maneira a permitir uma caracterização do sistema capitalista em diferentes períodos sob diferentes modelos. Admite-se que o capitalismo apresenta especificidades em momentos distintos de seu transcurso global, sem necessariamente alterar o centro vital do processo de 
alocação do recurso, onde se situa o fulcro do decurso de acumulação do capital. Porém este não abandona suas características e se mantém tão alienante quanto antes.

O estudo da base do capitalismo moderno é um protótipo das experiências subseqüentes das eras capitalistas anteriores, as quais tiveram como conseqüência, menos uma superação do que uma continuação das relações de produção. Neste movimento, as sociedades capitalistas, pré-existentes, arcaram com as mutações apresentadas pelo sistema e propagaram os novos conjuntos de valores universais adquiridos (DOBB, 1971; ARRIGHI, 1996).

5 A economia capitalista moderna é um imenso cosmos que veio para dominar a vida econômica, para educar e selecionar os sujeitos de quem precisa, mediante um processo de sobrevivência dos mais aptos. O espírito do capitalismo teve de lutar por sua supremacia contra um mundo inteiro de forças hostis (WEBER, 1967).

6 A fase embrionária de acumulação do capitalismo germina nas malhas da sociedade feudal e padece dos limites estreitos deste período (HOBSBAWM, 1979). Desse modo, o decurso da ruptura das bases da sociedade feudal foi dilacerando-se lentamente, cujo processo teve inicio no século XI e prolongou-se até o século XVI. Para alguns autores, nesse período permitiu-se generalizar ao contexto mundial como a era do capitalismo. Ainda que o esboço da produção capitalista fosse prematuro em algumas cidades do Mediterrâneo, a era capitalista só data do século XVI com o comercio e o mercado mundial, onde o poder capitalista disperso passa para um poder concentrado, no caso a fusão do Estado com o capital e começa a penetrar na produção em escala considerável. (MARX, 1977; DOBB, 1971; BRAUDEL, 1989; ARRIGHI, 1996).

7 A organização e o aumento da produção, a extorsão do trabalho, a prestação de serviços remunerados, seja por gênero ou em dinheiro, do contrato salarial, da propriedade privada, da retomada do comercio frente à circulação de moeda, do abastecimento de produtos para o mercado, do renascimento da vida urbana e da formação da classe burguesa, contribuíram para anunciar o desenvolvimento do sistema capitalista. A essência do capitalismo encontra-se no estado de espírito e no comportamento humano condizente a existência das formas econômicas de acumulação. A emergência de novas mentalidades influenciou e inspirou o modo de vida de toda uma época, de modo que contribuiu para legitimar o modo de produção capitalista vigente. (DOBB, 1971; MARX, 1977; BRAUDEL, 1989). Na trajetória do capitalismo, a partir da introdução do 'gene' do capital, torna-se claro que o sistema capitalista passou por uma longa marcha para chegar ao período maduro do capitalismo contemporâneo.

\section{As novas configurações do capitalismo contemporâneo}

8 O capitalismo contemporâneo não renunciou as bases do regime de acumulação financeira, em que os mercados e os operadores adquiriram certa importância (CHESNAIS, 2003), porém anunciou o desenvolvimento do regime capitalista através dos fatores cognitivos. $O$ capitalismo contemporâneo consagra-se por apresentar um novo modelo de reprodução do mundo e um novo modelo de acumulação. Ambos, centrado, sobretudo, nos movimentos do capital financeiro, na circulação de bens e serviços, na informação, na satisfação e na eficiência, do que situado somente na unidade de produção. Esta fase depende mais de uma atividade intelectual, comunicativa e/ou 
afetiva, criadora de signos e de subjetividades do que da própria estrutura produtiva materialista. De acordo com Pelbart,

"a produção de subjetividade, os processos vitais ricos em relações intelectuais e valores afetivos, passam a ocupar um lugar cada vez mais central do processo produtivo"(PELBART, 2003, p. 36).

9 Pode-se considerar que esta ordem capitalística incide na produção de desejo, subordinada às formas de inconsciente expressivo, sob os fluxos decodificados que se precipitam e confundem o sujeito. De modo que a produção materialista, agenciados pelos universos lingüísticos, pressupõe e condiciona a apropriação e a utilização do consumo pelo viés do capital. o desejo produz um imaginário que duplica a realidade como se houvesse um objeto sonhado por detrás de cada objeto real ou uma produção mental por detrás das produções reais (DELEUZE \& GUATTARI, 1996).

«(...) o capitalismo liberta os fluxos desejantes, mas nas condições sociais que definem o seu limite e a possibilidade da sua própria dissolução, de modo que contraria constantemente com todas as suas desesperadas forças o movimento que o impele para este limite $»$. (DELEUZE \& GUATTARI, 1996, p. 143).

10 O capitalismo iguala-se a ponto de uma máquina moderna que tem o objetivo de intervir no desejo e transformá-lo numa categoria fundamental da economia. O capitalismo tende para um limiar que liberta os fluxos de desejos num campo desterritorializado do sujeito e o incentiva a consumir.

11 As evidencias de que estamos sob o Império do Efêmero, contribuem para a espetacularização do real, imprimindo-lhe um sentido puramente ficcional. Esta artificialidade da vida, que se alimenta do processo posto em movimento pelo capital, empurra o sujeito sob a apoteose da sedução e para o declínio da referência. A imagem, instrumento das estratégias capitalistas, legitima a sociedade do consumo e contribui para tornar a racionalidade humana num imaginário puro. $\mathrm{E}$ isso influi sobre a razão do indivíduo na construção e reprodução de uma imagem distorcida e particular do mundo. Assim, o indivíduo torna-se prisioneiro daquilo que descreve e ao mesmo tempo compactua com o capitalismo (LIPOVETSKY, 1989; SFEZ, 1994).

12 O capitalismo contemporâneo inscreve-se no tecido social de forma a domesticar o homem através da linguagem e das relações cognitivas. Este sistema encontra na produção materialista daquilo que são consideradas comuns e naturais às maneiras de confundir o sujeito e levá-lo a consumir sob o signo do novo.

13 Na concepção de Hardt e Negri (HARDT \& NEGRI, 2000), as grandes potências industriais e financeiras produzem não apenas mercadoria, mas também subjetividades, ou seja, produzem um universo de linguagem que encerram por construir o simbólico e o imaginário. A subjetividade é encarada como produção social. Ela é essencialmente fabricada e modelada no registro social e assumida por indivíduos em suas existências particulares. (GUATTARI \& ROLNIK, 1986).

Desta forma, a produção da subjetividade, toma o lugar das coisas materiais e constrói desde o modelo de consumo até o mundo do consumidor. Esta cria o universo das necessidades, das relações sociais, dos corpos e mente. A sociabilidade entre os indivíduos e o mundo passa, no contexto do capitalismo contemporâneo, pela a artificialidade das coisas. Segundo Moles :

"As relações do indivíduo com o meio social passam, a partir de agora e fundamentalmente, pelos objetos e produtos transformados nas expressões mais 
tangíveis da presença e da sociedade em seu ambiente, desde o momento em que

tomam o lugar das coisas naturais" (MOLES, 1975, p. 12). capital, as empresas souberam utilizar dessas novas ferramentas para persuadir o consumidor desguarnecido. Isto é, as empresas utilizam, cada vez mais, das ferramentas da comunicação social para assegurar os objetivos intencionais, quanto à mercadoria, do que as realizações proporcionadas. Para Raffestin,

“(...) fizemos da imagem um 'objeto' em si e adquirimos, com o tempo, o hábito de agir mais sobre as imagens, simulacros dos objetos, do que sobre os próprios objetos." (RAFFESTIN, 1993, p. 145)

Portanto, pode-se refletir que as empresas não existem fora dos consumidores. Estes que são objeto de sua manutenção no mercado. Conforme Marx:

“(...) a produção não produz somente um objeto para o sujeito. A produção produz, portanto, o consumo, primeiro fornecendo-lhe materiais, segundo deturpando o modo de consumo e, terceiro, excitando no consumidor a necessidade dos produtos colocados por ela como objetos. Logo, ela produz o objeto de consumo, o modo de consumo, e a tendência para o consumo" (MARX, 1977, p. 210).

Marx, já apontava que a produção cria os objetos de consumo, e o consumo cria o sujeito para esse objeto, mas além de criar o sujeito para esse objeto, na contemporaneidade, o consumo inventa todo espaço que esse sujeito faz parte. A empresa não cria o objeto (a 
mercadoria), mas o mundo onde o objeto existe. Ela não cria tampouco o sujeito (trabalhador e consumidor), mas o mundo onde o sujeito existe (LAZARATTO, 2004).

Assim, as empresas permitem que o sujeito expresse como sua própria extensão territorial. De forma que, o território torna-se resultado também, de ações conduzidas por sujeitos. Neste caso, o valor do território é existencial: ele circunscreve, para cada um, o campo do familiar e do vinculante, mas as distâncias em relação a outrem e protege do caos (DELEUZE, 1997), contudo esse território também é volátil e seu produto esta relacionado com as vantagens oferecidas pelas empresas ao consumidor e de como o consumidor se identifica com a empresa. Para tanto, as empresas trabalham de forma a anular o efeito das possibilidades do consumidor em reaver seus conceitos sobre aqueles produtos oferecidos e não perder de maneira nenhuma o território conquistado para as demais concorrentes.

Essas empresas foram assumindo, cada vez mais, o papel de representantes nas economias capitalistas por meio da internacionalização da produção que o permitiu a emergência de um mundo globalizado. Desse modo, apresentar-se-ão no cenário mundial as multinacionais, as quais contribuíram para que os espaços econômicos nacionais não mais coincidissem com os espaços geopolíticos dos capitais.

Para isto, as companhias mudaram para uma mentalidade internacional e começaram a dedicar-se a uma intensa estratégia de produção global em plano a uma política agressiva de penetração em outros mercados nacionais.

Além de dominar o setor de exportações as empresas multinacionais passaram a investir em unidades de produção e comercialização destes produtos em outros países, distintos da localização da matriz. Consequentemente, as empresas ampliaram a presença em outros lugares. Para Hymer (HYMER, 1983, p. 47), "as grandes empresas dos Estados Unidos começa-se a deslocar-se para países estrangeiros logo após se completar sua integração em escala continental" e que "as grandes empresas de todos os países terminaram, cada vez mais, por 'ter como habitat o mundo"' (idem, p. 114). Há exemplo das grandes empresas norte americanas destaca-se a rede varejista Wal-Mart que vive, na década de 1990, o início do seu processo de internacionalização.

\section{O processo de internacionalização da rede varejista Wal-Mart}

27 Para evitar a derrocada ou falência e garantir a prosperidade, a rede varejista Wal-Mart preferiu optar pela busca de novos mercados. No entanto, o processo de internacionalização da empresa, no início da década 1990, só ocorreu após a rede varejista minar a concorrência e atestar sua dominação no setor de varejo norte-americano.

“(...) a Wal-Mart só passou verdadeiramente a ter consciência de seu papel influente no varejo no final dos anos 80. Embora a primeira loja Wal-Mart tenha sido inaugurada em 1962, a superloja modelo só decolou em 1988 e foi apenas em 1991 que a Wal-Mart - que na época inaugurava 150 lojas de desconto por ano ultrapassou a Kmart e a Sears e se tornou a força mais poderosa no varejo americano" (KLEIN, 2003, p. 156).

A fase foi marcada pela modernização da estrutura administrativa. As operações comerciais foram, então, monitoradas por dispositivos tecno-informacionais que permitiram conectar a rede varejista com os principais fornecedores e, também, controlar 
o estoque das centrais de distribuição. Esta revolução tecnológica ampliou os horizontes da empresa e a colocou em contato com outros mercados consumidores. Esta fez uso das estratégias capitalistas para ostentar sua dominação no setor varejista e se tornar um potencial concorrente nos novos mercados.

O processo de internacionalização iniciou-se no México, em 1991. A rede varejista WalMart em menos de 10 anos, no México, já assumia o cargo de maior empresa do setor. A política de preço baixo controlou o mercado e, indiretamente, forçou as pequenas e médias empresas do setor filiar-se a bandeira norte-americana. A estratégia política da rede avança pelos principais países da América Latina. Hoje, em 2011, através do processo de internacionalização da empresa, pode-se encontrar estabelecimentos da rede, nos seguintes países: Argentina, Brasil, Canadá, Chile, China, Costa Rica, El Salvador, Guatemala, Honduras, Índia, Japão, México, Nicarágua e Reino Unido. Como conseqüência, a empresa, após o processo de internacionalização, multiplicou sua venda liquida em "equações logarítmicas".

Gráfico1: Venda líquida por ano fiscal

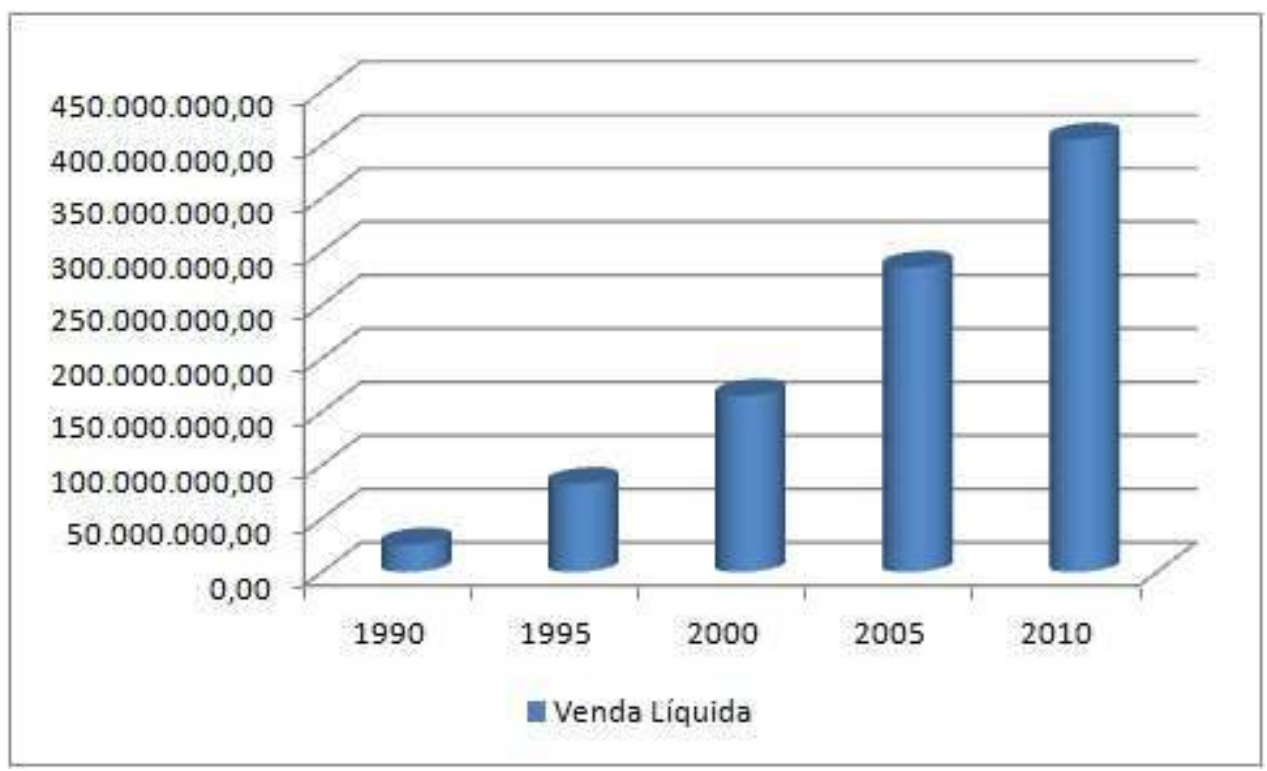

Fonte: Annual Reports Wal-Mart Stores (1989-2011) 
Gráfico 2: Lucro líquido por ano fiscal

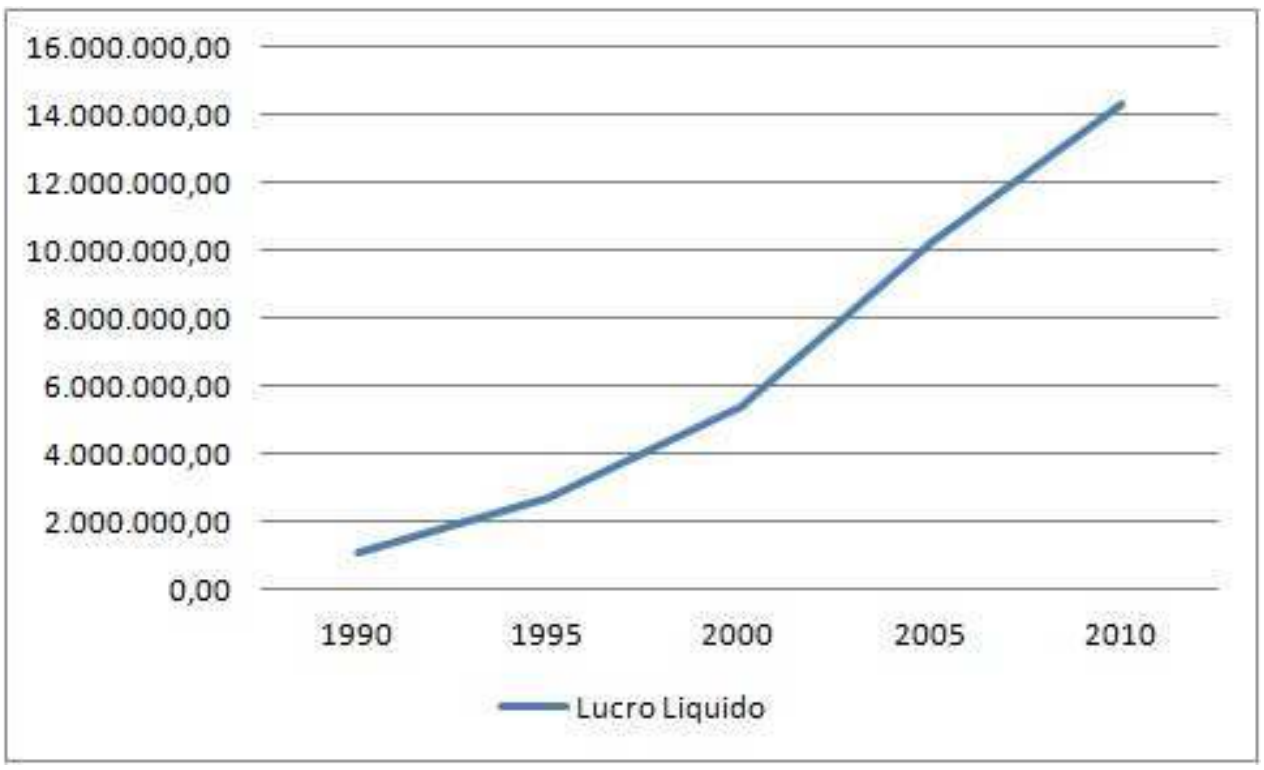

FONTE: ANNUAL REPORTS WAL-MART STORES (1989-2011)

O efeito Wal-Mart atravessou os continentes e os oceanos levando a cultura capitalista da empresa a mercados que sustentam uma classe média emergente e um contingente de possíveis consumidores.

\section{Wal-Mart e a cultura capitalista: implicações no espaço geográfico}

31 O professor de história Nelson Lichtenstein, autor do livro "Wal-Mart: The face of Twenty-First Century Capitalism, da Universidade da Califórnia, advertiu que em cada período do capitalismo norte-americano encontra-se um tipo de empresa como padrão, provocando uma revolução nas estruturas sociais, econômicas e política do mundo capitalista. Desta forma, uma nova organização do trabalho e da produção, um modelo mais eficiente e lucrativo e novos acordos entre as diversas classes da sociedade emergem a exemplo de controlar o mercado capitalista mundial a favor das empresas.

Entretanto, no século XIX, tivemos a presença da Pennsyvania Railroad, maior empresa de ferrovias norte-americana; no início do século XX foi a vez da Ford; em meados do século a General Motors seguido pela a Microsoft e o McDonald's (SADER, 2005). Agora no início do século XXI, a rede varejista Wal-Mart aponta como modelo de empresa capitalista. Esta impõe lógicas de dominação no território e transforma o mundo da concorrência através de um sistema de produção, de distribuição e de emprego multinacional e fortemente integrado.

«Esse é o modelo de empresa capitalista do século XXI, que combina superexploração dos trabalhadores na periferia do sistema com superexploração dos trabalhadores imigrantes dentro dos Estados Unidos, proibição de sindicalização e expropriação dos direitos sindicais, incluída a proibição de sindicalização » (SADER, 2005, p.40) 
33 A rede varejista norte - americana foi capaz de "alterar o zoneamento das cidades americanas, estabelecerem padrões de salários e até mesmo conduzir negociações diplomáticas com outros países" (GREENHOUSE, 2004, p. A28). A empresa exigiu mudanças nas vias de acesso à loja, na construção de facilitadores urbanos, na instalação de semáforos nas ruas próximas à unidade, entre outros instrumentos e infra-estrutura responsáveis para reproduzir a lógica burguesa da rede varejista.

As melhorias viárias é fruto de uma relação entre o poder local e o empreendedor e não uma relação de responsabilidade social. Estas atendem prioritariamente à reprodução do capital e não às necessidades postas pela sociedade. O que se conclui que a ordem social é determinada pela dinâmica econômica.

Desta maneira, o gigantismo da rede Wal-Mart, que abastece as residências de quase $80 \%$ das famílias americanas, força os fornecedores a expor seus produtos nas estantes do varejista. As vendas da companhia Wal-Mart somam, todo mês: 320 milhões de latas de Coca-Cola, 250 milhões de litros de água mineral Nestlé e 101 milhões de litros de leite de sua marca própria, Great Value. Além de representar, como venda dentro dos EUA, 1 CD ou DVD em cada 5 compradores, 1 tubo de pasta de dente em cada 4, 1 berço de bebe em cada 3, 1 boneca Barbie a cada 2 segundos (GUROVITZ, 2005). o preço baixo, a qualidade do produto, o atendimento diferenciado e a garantia de venda aos fornecedores são valores desleais compartilhados em todas as unidades da rede.

Uma corporação poderosa como uma nação, que compra produtos a preço de banana em países asiáticos, compactuando com trabalho semi-escravo, para revendê-los garfando suculentas margens de lucro. Uma empresa de tentáculos gigantescos, capazes de destruir o pequeno comércio e de espremer cada centavo nas negociações com fornecedores, até levá-los a bancarrota. Um empregador cruel, que paga os piores salários do mercado, descrimina mulheres e minorias, desdenha planos de saúde e combate ferozmente os sindicatos - não há um único sindicalizado entre 1,3 milhões de americanos que trabalham para o Wal-Mart. Um grupo de fanáticos moralistas, capazes de censurar CDs, filmes e livros, de proibir remédios legais - como uma versão da pílula do dia seguinte - e de tentar impor ao resto do planeta a cultura caipira do Meio-Oeste americano (GUROVITZ, 2005, p. 24-25).

37 Na China, por exemplo: a fábrica da Wal-Mart paga de US\$ 0,13 a US\$ 0,35 por hora trabalhada, com turno de 10 a 12 horas, entre 6-7 dias por semana, com condições irregulares: horas extras forçadas, multas severas pela recusa ao trabalho, sem contrato legal e sem benefícios; os prédios, sem saída de incêndio, dormitórios sujos e apinhados (KLEIN, 2003)

Ademais, a rede varejista Wal-Mart se recusa a vender qualquer material que possa ferir a integridade da imagem da loja, uma vez que esta acredita que ser uma loja de família é a essência de seu sucesso financeiro. Segundo Klein, “o caso mais conhecido envolveu a recusa da cadeia em vender o segundo disco do Nirvana, In Utero, embora o álbum anterior da banda tenha recebido quatro disco de platina, por fazer objeção á arte da contracapa, que retratava fetos" (KLEIN, 2003, p. 191). Diante de uma perda estimada de 10\% (a participação da Wal-Mart na venda de disco nos EUA na época), a Warner e o Nirvana voltaram atrás e mudaram a contracapa. Eles também mudaram o título da canção 'Rape Me ('Estupre-me') para 'Waif Me' ('Abandone-me'). Assim, os produtos de entretenimento, que representam somente uma fração de seus negócios, lançam versões higienizadas de seu trabalho e apresentam, para a avaliação da rede, exemplares que 
serão comercializados antes de iniciar o seu processo produtivo. A partir de estratégias pontuais a rede varejista Wal-Mart construiu o seu império no ramo. Neste setor, em 2005, a "Wal-Mart detém sozinha $47 \%$ das vendas gerais das doze maiores empresas varejistas mundiais" (DUPAS, 2005, p. 95).

No Brasil, a alta penetração da rede varejista norte-americana Wal-Mart estabeleceu uma política forte de concorrência e elevou a disputa entre as empresas líderes, Carrefou, Pão de Açucar e Wal-Mart. Esta tensão aumentou a participação do mercado entre as 3 maiores bandeiras frente aos consumidores. Estas sozinhas controlam, comparada com as 20 maiores redes supermercadista do país, aproximadamente $75 \%$ das vendas liquidas do setor no Brasil. Dado que o resultado objetivado pela concorrência e configurado no cenário brasileiro é a acumulação de capital nas mãos de poucos e, por conseqüência, conduz a um quadro aparente de monopólio. Como diria Marx "os únicos motivos que põem em movimento a economia política são a avareza e a guerra entre os ávaros, a competição" (MARX, 1975, p.158).

Diante disso, a intensificação da disputa pelo cliente, exige das empresas estender os seus tentáculos no solo fecundo do consumo, por meio de suas estratégias modulares de intervenção, sedução e captura que, a um só tempo direcionam e padronizam os interesses da sociedade (DELEUZE, 1997). A interceptação desses consumidores parte de um controle, cada vez menos visível e material e cada vez mais sutil e imaterial (FOUCAULT, 1989).

\section{Considerações finais}

41 Contudo, a estratégia de globalização da rede varejista é marginal ao interesses do grupo. o fortalecimento interno no mercado americano ainda é o objetivo principal tendo em vista que a menor parcela do valor arrecadado vem de outros países. Apesar da rede varejista ter quase $40 \%$ das lojas operando fora dos EUA, os $80 \%$ de residências abastecidas por produtos de bandeira Wal-Mart ou produtos vendidos no estabelecimento desfocam os interesses da empresa em investir no mercado externo. Também, apesar das crises de 2008 e 2009, é fato considerar que existe uma disparidade de renda entre os consumidores dos diferentes países onde a empresa possui sede. Além de considerar o território norteamericano como um país genuinamente consumista.

42 A rede varejista Wal-Mart transita entre as funções de vendedor de bens de consumo diários a agente de produção de significados e modos vivendi, já que imprime no slogan "every day low price" a "oportunidade" dos consumidores em experimentar o tamanho da força de sua marca. A relação entre consumo e produto se converte em consumo consumido, onde o consumidor torna-se produto-objeto e o produto adquiri autonomia frente ao desejo do consumidor.

43 A trajetória do Wal-Mart aponta também para um esforço de retomada de praticas sociais calcadas em relações de fidelidade e subsunção que faz com que a imagem consumidor ideal se ajuste a ilusão confortante de relações de natureza domésticas ou familiares. As faces de aderência que se constituem nas relações entre a empresa e o consumidor são peculiares às formas com que a apropriação da subjetividade se refaz a cada instante pelas investidas da em empresa em mercados ainda não cativos.

Em suma, estamos inteiramente de acordo com Sader acerca do modelo político gerencial adotado pela rede Wal-Mart relacionado à combinação entre superexploração dos 
trabalhadores, sobretudo migrantes, e as formas de subordiná-los às regras arbitrárias da empresa, bem como a assertiva de Marx a respeito da produção do consumo como fator de excitação, no consumidor, de desejos por objetos que são em si mesmos e ulteriormente objetos do consumo.

\section{BIBLIOGRAFIA}

ARRIGHI, G. O longo século XX: dinheiro, poder e as origens de nosso tempo. Rio de Janeiro: Editora UNESP, 1996.

BASKER, E. The Causes and Consequences of Wal-Mart's Growth, unpublished paper, University of Missouri, 2007.

BRAUDEL, F. A dinâmica do capitalismo. $3^{\text {a }}$ ed. Lisboa: Teorema, 1989.

CHESNAIS, F. A Nova Economia: uma conjuntura própria à potência econômica estadunidense. In: CHESNAIS, François, DUMÉNIL, Gérard; LÉVY, Dominique, WALLERSTEIN, Immanuel. Uma nova fase do capitalismo? São Paulo: Cemarx, 2003.

DELEUZE, G. Conversações. São Paulo: Ed. 34, 1997.

DELEUZE, G., GUATTARI, F. O que é a filosofia? São Paulo: Editora 34, 1992.

DUPAS, G. Atores e poderes na nova ordem global: assimetrias, instabilidades e imperativos de legitimação. São Paulo: Editora UNESP, 2007.

DOBB, M. A evolução do capitalismo. Rio de Janeiro: Zahar, 1976.

GREENHOUSE, S. Wal-Mart intriga intelectuais dos EUA. Sociólogos e historiadores fazem simpósio só para tentar entender o fenômeno da ultrapoderosa cadeia varejista. Folha de S.Paulo, Caderno Mundo, 18 de abril de 2004, p. A28.

GUATTARI, F., ROLNIK, S. Micropolítica: cartografias do desejo. Petrópolis: Vozes, 1986.

GUROVITZ, H. O poderoso Wal-Mart: como um empório interiorano se transformou na maior e mais influente empresa do mundo. Revista Exame, São Paulo, 03 ago., 2005. p.22-28.

HARDT, M.; NEGRI, A. Império. Rio de Janeiro: Editora Record, 2000.

HOBSBAWM, E. J. Da Revolução Industrial Inglesa ao Imperialismo. Rio de Janeiro: ForenseUniversitária, 1979.

HYMER, S. Empresas Multinacionais: a internacionalização do capital. Rio de Janeiro: Edições Graal, 1983.

KLEIN, N. Sem logo: a tirania das marcas em um planeta vendido. Rio de Janeiro: Record, 2003.

LAZZARATO, M. Créer des mondes. Capitalisme contemporain et guerres esthétiques. Multitudes, 15, Art Contemporain. La recherche du dehor. Paris: Hiver, 2004.

LIPOVETESKY, G. O império do efêmero. São Paulo: Companhia das Letras, 1989.

MARX, K. Contribuição à crítica da economia política. SP: Editora Martins Fontes, 1977. 
MARX, K. Manuscritos Econômico-Filosóficos. Lisboa: Edições 70, 1975

MOLES, A. O. Kitsch: a arte da felicidade. São Paulo: Editora Perspectiva, 1975.

PELBART, P. P. Vida Capital: ensaios de biopolítica. São Paulo: Iluminuras, 2003.

RAFFESTIN, C. Por uma geografia do poder. São Paulo: Ática, 1993.

SADER, E. O modelo capitalista do século 21. Caros Amigos, Ano VIII, oํ 96, março, 2005.

SFEZ, L. Crítica da comunicação. São Paulo: Edições Loyola, 1994.

WEBER, M. A ética protestante e o espírito do capitalismo. São Paulo: Livraria Pioneira, 1967.

\section{RESUMOS}

$\mathrm{O}$ artigo tem como finalidade apresentar as metamorfoses que marcaram o capitalismo contemporâneo e suas implicações no espaço geográfico. Assim, toma a rede varejista norteamericana Wal-Mart como exemplo de empresa capitalista do século XXI. Conclui-se que esta não cria a mercadoria, mas o mundo onde a mercadoria existe.

The article aims to introduce the metamorphoses that defined contemporary capitalism and its implications in the geographic space. It has, therefore, the retailer Wal-Mart (U.S.) as an example of capitalist enterprise of XXI century. And with this it is possible to conclude that the company does not create the commodity, but the world where the commodity exists.

Cet article a l'intention de présenter les métamorphoses du capitalisme contemporain et leurs impacts sur l'espace géographique. Il s'appuie sur le réseau nord-américain Wal-Mart comme exemple d'une entreprise capitaliste au XXIème siècle. À partir de ses pratiques, on peut conclure que ce n'est pas l'entreprise qui crée la marchandise, mais le monde au sein duquel la marchandise existe.

\section{ÍNDICE}

Mots-clés: capitalisme, espace géographique, réseau, marchandise, Wal-Mart

Palavras-chave: capitalismo, espaço geográfico, rede, mercadoria, Wal-Mart

Keywords: capitalism, geographic space, network, commodity, Wal-Mart

\section{AUTORES}

\section{PEDRO HENRIQUE FERREIRA COSTA}

Doutorando em Geografia pela Universidade Estadual Paulista Júlio de Mesquita Filho (UNESP

- Rio Claro). Bolsista CAPES. E-mail: ferreiracostaph@gmail.com

\section{PAULO ROBERTO TEIXEIRA GODOY}

Doutor em Geografia pela UNESP e Professor Assistente Doutor da Universidade Estadual Paulista Júlio de Mesquita Filho (UNESP - Rio Claro). E-mail prtg@rc.unesp.br 